NBER WORKING PAPER SERIES

\title{
EFFECT OF MINIMUM WAGES ON HUMAN \\ CAPITAL FORMATION
}

Jacob Mincer

Linda Leighton

Working Paper No. 441

\author{
NATIONAL BUREAU OF ECONOMIC RESEARCH \\ 1050 Massachusetts Avenue \\ Cambridge MA 02138 \\ February 1980
}

We are grateful to the National Science Foundation and the Sloan Foundation for their support. The research reported here is part of the NBER's research program in Labor Studies. Any opinions expressed are those of the authors and not those of the National Bureau of Economic Research. 
Effects of Minimum Wages on Human Capital Formation

\section{ABSTRACT}

The hypothesis that minimum wages tend to discourage on the job training is largely supported by our empirical analysis. Direct effects on reported job training and corollary effects on wage growth as estimated In microdata of the National Longitudinal Samples (NLS) and Michigan Income Dynamics (MID) are consistently negative and stronger at lower education levels. Apart from a single exception, no effects are observable among the higher wage group whose education exceeds high school.

The effects on job turnover are: a decrease in turnover among young NLS whites, but an increase among young NLS blacks and MID whites. Whether these apparentiy conflicting findings on turnover reflect a distinction between short and long run adjustments in jobs is a question that requires further testing.

Linda Leighton

Center for the Soctal Sciences

S.I.A. Building, Room 816

Columbia University

New York, New York 10025
Jacob Mincer
Department of Economics
S.I.A. Building, Room 808
Columbia University
New York, New York 10025

(212) $280-3676$ 
EFFECTS OF MINIMUM WAGES ON HUMAN CAPITAL FORMATION

The two major avenues of human capital formation are schooling and job training. But the effects of minimum wages on human capital can be quite different in the two cases. Theoretically, the effects of imposition, extension, or hikes of the minimums and of their coverage on training on-the-job are unambiguous: job-training is discouraged. But schooling may be discouraged or encouraged. Thanks to recent research, especially that of Mattila $(1978,1979)$ it would appear that schooling is encouraged by the minimum wage, an effect opposite to the expected job training consequences.

As things stand, it seems that we do not, as yet, have any evidence on the theoretically predictable case of job training, ${ }^{I}$ while we do have an empirical answer to the theoretically ambiguous prediction about effects on schooling. In this paper we try to fill two gaps: we explore the theoretical considerations regarding effects of minimum wages on schooling, and bring together evidence on the job training effects.

\section{Effects on Schooling: Theoretical Considerations and Research}

The basic question here is whether minimum wages increase or decrease the rate of return to further schooling for youngsters at the relevant levels of earning capacity (further schooling at this level is likely to mean completion of high school and more up to perhaps junior college.)

'Work, in progress, by Hashimoto (1979) came to our attention after completion of our research. 
The same question was put forward in a more general form by one of the present authors (Mincer, 1976) in terms of labor mobility: Since the increased wage in the covered sector is an attraction but the reduced probability of employment a deterrent, will labor on balance move to or from the covered sector when minimum wages are imposed or raised? The answer depends on whether the minimum wage hike raises or lowers wage prospects in the covered sector. Define "wage prospects" as $\hat{w}=P_{m} \cdot w_{m}$, where $P_{m}$ is the perceived ${ }^{2}$ probability of employment in the covered sector. If $\hat{w}$ falls (because $p_{m}$ falls by more than the increase in $w_{m}$ ) labor moves out of the covered sector to the not-covered, reducing its wage $\left(w_{n}\right)$. With unchanged prospects in the non-market, labor moves out of the market as well. The flows continue, until in equilibrium $\hat{w}=w_{n}=\widetilde{w}$ (where $\hat{w}$ is the non-market shadow wage.) It is not easy to measure $P_{m}$, even if a

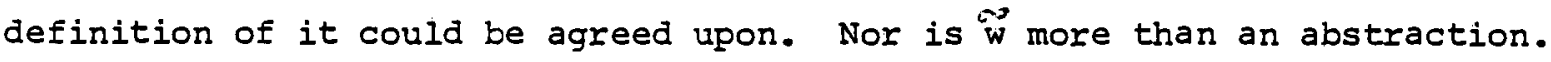
$\mathrm{w}_{\mathrm{n}}$ might be observed, but no one has tried to do so.

The evidence observed in the 1976 study and in a Canadian study (Swidinsky, 1978) was the direction of movement: from market to nonmarket. This direction of movement is implied by a drop in market wage prospects, and rejects the hypothesis of their improvement via the minimum wage.

${ }^{2} \hat{w}$ is the "expected wage" in the covered sector, in the sense of a mathematical expectation, if we assume risk neutrality. "Wage prospects" are less than "expected wages" with risk aversion. 
Now, if the evidence is correct, it follows that the profitability of schooling is increased by the minimum wage hike. Let $s_{0}$ be the maximal schooling attainment of youngsters facing wages near the minimum, so their wage prospects are $\hat{w}$. Let $s_{1}$ be the minimal schooling attainment at which wages $w$ are safely above minimum wages. In the simplest model, the return to schooling is measured by $w_{1}-\hat{w}$, and its (opportunity) cost by $\hat{w}$. A drop in $\hat{w}$ raises returns and lowers costs, and so improves the profitability of schooling above $s_{0}$ (though not above $s_{l} \cdot$ ) Had $\hat{w}$ increased as a consequence of minimum wages, profitability of schooling in the $s_{0}-s_{1}$ interval would have fallen. In that case we would have observed a decrease in school enrollment and at the same time an increase in the labor force, as well as an increase in unemployment exceeding that of disemployment resulting from the minimum wage! This scenario is rejected by the empirical observations.

Thus the increase in school enroliment is predictable, given the observed effects of minimum wages on labor force participation. The link is economic, via changes in rates of return, not merely tautological in the sense that schooling is part of the non-market.

It is worth noting that the question of effects of minimum wages on the volume of welfare payments is analogous, indeed identical, to the question about effects on school enrollment. A priori, one could argue either way. Indeed, according to a survey by West and McKee (1979) inducement to work has become a major argument in favor of minimum wages: 3

\footnotetext{
${ }^{3}$ West and McKee (1979), p. 11
} 
A final purpose of the minimum wage, articulated only since the advent of widespread social security programmes, has been that of providing incentive to work for employees who are tempted to rely instead on pensions, unemployment, or welfare benefits. Most governments recognise (at least informally) the intimate relationship between social assistance and low-wage employment (since individuals may switch back and forth frequently) by attempting to set minimum wages somewhat above that which a single person can expect to earn from such schemes. A latter-day purpose of minimum wage legislation, therefore, is to induce workers to search for jobs.

It is clear now, given the evidence on labor force participation and on enroliment effects of minimum wages, that the inducement argument is not valid. Indeed, the logical conclusion is to the contrary: minimum wages induce welfare, not work. However, without more direct empirical evidence, this conclusion still remains in the realm of speculation.

Returning to the effects on schooling, it has been argued that these effects are asymmetrical: ${ }^{4}$ school enrollment is likely to increase for the non-poor and decrease for the poor. By extension a similar difference might be observed between Whites and Blacks. But the theoretical basis for this prediction is weak. We would expect that the profitability of longer schooling would increase for all groups. Indeed, the lower the pre-minimum wage, the greater is the $(g)$ reduction in $\hat{w}$, if it falls; according to the Mincer (1976). model. Consequently, the rate of return to schooling increases more for the lower sub-minimum wage workers than for others, and the inducement into longer schooling could be strong or stronger among the poor. Mattila's empirical finding that school enrollment increased for both Blacks and Whites is consistent with the negative effect of minimum wages on labor force participation in both groups (Mincer, 1976). Mattila actually finds that black response coefficients are somewhat stronger than those of the whites, which need not be surprising.

${ }^{4}$ See Welch (1974) and Ehrenberg-Marcus (1979). 
Mattila finds also that work of black students has decreased or not increased in contrast to the growth of participation among white students. These findings are supported by aggregate (CPS) data (Freeman and Medoff, 1979) and suggest possible effects of the welfare system. Since school enrollment of children who are 18 or less is a condition of receipt of welfare payments in eligible families, we would conclude that increases in welfare enrollment induce reported school enrollments in such families. At the. same time their reported work activities are likely to be reduced.

It is true, of course, that both the financing and the motivational (ability) factors produce a shorter schooling career of the poor compared to the non-poor. This is true both before and after minimum wage hikes, and levels should not be confused with change. The non-student proportion of the relatively poorer population remains larger. This group must rely on the labor market for personal economic advancement. It, therefore, bears the brunt of the adverse minimum wage effects on job training.

\section{Effects on Job Training}

While minimum wages may be expected to prolong the length of schooling, they create obvious barriers to job training. Job training must be financed, at least in part, by the worker or apprentice, usually in the form of a reduced initial wage. This means that even if current productivity of some of the employed youngsters warrants paying the minimum wage, job training is precluded for them since its provision would require paying initially a

5 wachter and kim (1979) found also that enrollment rates for all young (16-24) blacks were lower than those of young. whites in 1965, but the situation was reversed in 1978 . 
subminimum. 6

This effect is another source of an increased demand for more schooling: young persons with the ability and motivation to invest in their human capital are lead to substitute longer schooling for job training. ${ }^{7}$ Moreover, the additional schooling enables them to enter higher (than minimum) wage jobs and reopens the possibility of subsequent job training as well.

Thus the labor market difficulties which the minimum wage generates. for low wage young workers are twofold: loss of jobs for some where wages are initially below the minimum and loss of opportunities for training and careers even for those whose initial productivity is worth as much or somewhat more than the minimum wage.

We may note, at this point, that minimum wages will tend to discourage the formation of both "general", that is transferable skills, as well as firm-specific capital, although the effects on the latter may be weaker to the extent that the firm is willing to bear costs of training the worker. Several types of supply responses may be expected as a result of minimum wages: Those who are intellectually and financially able to prolong schooling will do so, even if their interests are primarily vocational and they would have preferred job training to staying in school. One may speculate that the growth of junior colleges and of private vocational schools, as

6 This conclusion was stated earlier by Rosen (1972) and Feldstein (1973). The discouragement of training could be avoided by separating payments (of employers to workers) for work from payments (of trainees-workers to employers) for training. It is the netting out of the two transactions that creates problems even for workers whose initial value productivity is not subminimum.

7 Even if employers were indifferent between wage "packages" with or without training as long as labor costs per hour are the same, workers who opt for job training are worse offwhen the higher minimum wage without training replaces the lower wage with training. For an elaboration of the "wage package" analysis see Wessels (1979), in progress. 
well as the growing demand for vocationalism in college curricula, is partly a reflection of this response. And so is also the growing tendency of students to combine school with market work. ${ }^{8}$ student work is also partly encouraged by provision of the Fair Labor Standards Act which creates differentials and exceptions for students. The transition to full-time work at wages above the minimum wage hurdle is made easier by part-period and part-time work while at school. Although jobs of students are usually low-skilled and casual, they provide some experience and some measure of financial independence. The "dead-end" nature of many of these casual jobs creates no particular anxiety, since they will be left behind as soon as the student has graduated and acquired more rewarding capacities.

The early labor market difficulties produced by the minimum wage are not easily surmounted by youths who are either unwilling or unable to prolong their schooling. Since opportunities for job training leading to advancement on the job are blocked by the minimum wage for some of them, the young school dropouts must choose jobs with little promise for advancement or become a labor market dropout as well. Non-participation in the labor market, which is induced by the minimum wage, may be financed by the family, by unreported market or illegal activities, or by the welfare system.

The non-students who do not drop out of the labor market despite their low productivity must contend with several obstacles: greater difficulties (longer unemployment) in finding jobs in the covered sector, and lesser growth on the job because of the reduced availability of training

8 This is shown to be the case in Mattila's work. There are, of course, additional reasons for this trend which need not concern us here. 
on the job. Although it may seem strange to assert that higher wages increase turnover, this can happen in the longer run when minimum wages are raised, since the reduction of fim-specific training in jobs which contain it reduces the cost of turnover for the worker and for the employer. More generally, employers can be expected to adjust to the raised minimum wage in several ways: by (1) reducing employment of the relevant workers and substi-. tuting capital and a somewhat higher quality of labor for them and (2) by reducing these components of the wage package (such as training) which are not included in (netted out of) paid-out wages. The implications for changes in turnover in the long-run are ambiguous, because an upgrading of labor may well reduce it, while a downgrading of the wage package (in terms of reduced training opportunities) is likely to increase turnover. However, the workers initially exposed to the minimum wage hike, some of whom may be later replaced, will experience an increase in turnover because of the curtailment of job training opportunities. In the short-run, prior to full adjustment, the effects on turnover are also ambiguous, since quits will be reduced ${ }^{9}$ and layoffs increased in the covered sector.

We may sumnarize the relevant implications of minimum wages as follows: (1) Induced prolongation of schooling coupled with increased part-time work of students (except for those on welfare.) (2) Reduced pace of job advancement, and (3) Eventually increased turnover for those non-students whose jobs contained specific training opportunities.

9 Indeed, in the only study that came to our attention, Mixon (1978) found that minimum wages reduce quits in manufacturing industries. The estimated coefficients of the Koyck distributed lag on his quarterly data imply that this effect vanishes almost totally within a year. 


\section{Empirical Analysis of Effects on Job Training}

Our empirical work is designed to explore the effects of minimum wages on job training. This task is difficult to carry out in any direct sense: We have no time series on changes in the provision of training that could be matched up with changes in minimum wage levels and in coverage. Even if such data on training were available, it may not be reasonable to expect a clear correlation between the short-run variation in minimum wages and the longer-tenm policies of finms regarding training of their employees. Indeed, the oscillation of minimum wages around a relatively fixed ratio to average wages and the past updrift in coverage should have convinced employers to view the minimum wage as permanent and to respond in terms of long-run adjustments.

The less direct implications about wage growth and turnover can neither be observed nor correlated with minimum wages in aggregate time series. Our approach is to analyze longitudinal micro-data in which both wage growth, turnover, and some responses to questions about training are available. Following Ehrenberg and Marcus (1979) we differentiate our sample of workers by state of residence. ${ }^{10}$ First we estimate differences in wage levels across states for the "same worker". These differentials serve as inverse indicators of the differing potential importance of the minimum wage across states. That is, the lower the (standardized) state wage, the higher the ratio of minimun to state wages, since the minimum wage is basically uniform across states.11 The other state variable is the ratio of covered

10We are grateful to Ehrenberg and Marcus for providing the identification of states in the NLS which they obtained laboriously. Identification of states in MID data is simpler and more accurate.

I There are two sources of variation: differential proportion of coverage by state laws and differences in levels of state minimum wages. On average, about 10\% of coverage is state coverage. The variation so introduced in the minimum wage level is of minor magnitude, which we ignore. 
employment to total nonagricultural employment, available in published data. 12 Following the usual formulation, 13 we combined the two variables into one: $\frac{\text { Cov }}{1+s w}$ ' where Cov is state coverage and sw is the percent wage differential. Here coverage is multiplied by $\frac{1}{1+s w}$, which is proportional to the ratio of the minimum to the standardized state wage.

The effects of minimum wage variables are then explored in regressions where wage growth, job tenure, and training dummies alternate as dependent variables. These effects are estimated net of a set of factors which we selected as determinants of the dependent variables. In what follows, we describe the analysis of data from the 1973 and 1975 Michigan Panel of Income Dynamics for a panel of white men, 14 and for white" and black young men in the NLS panels for the two periods from 1967 to 1971 . We restrict both samples to non-students. 1967 is the year in which substantial increases in the minimum wage and its coverage went into effect. The main reason for choosing the earlier period in NLS was the availability of state identifications. The later period in MID was preferable because an appropriate question on training became first available in 1976. Although the data sets are not exactly comparable, the later MID sample is more likely to represent the long-run effects than the NLS sample.

12 The coverage ratio includes, in the numerator, the total number of private and public sector employees covered by FLSA as of $\left(c_{f}\right)$ Feb. 1, 1970 (note that the last change of coverage prior to 1970 was 1966) plus the number covered by state minimum wages only $\left(c_{s}\right)$. The denominator is the total number of private and public nonsupervisory employees in the state in 1969. 13 The multiplicative formulation is theoretically superior to the linear, though it need not be the best (cf. Welch,1974).

14The sample of black men was much too small in MID. The empirical analysis was not extended to women. 
Table I presents a list of dependent and independent variables used in each of the four regression analyses of wage functions, wage growth, job tenure, and training.

\section{(1). Wage Functions}

Our first step is to estimate the relevant state differences in wages. Crude differences in wages will not do, because we want to know the effects of imposed changes in the price of labor, and not whether labor of higher "quality" receives more or less training. Consequently we estimate wages facing the "same worker" in various states by running wage functions across all individuals in the sample, using a standard set of wage deteminants such as schooling, experience, length of tenure, as well as a number of other personal and job characteristics listed in Table 1. State dummies were added to the set of independent variables. Their coefficients represent estimates of wage differences (for an average worker with the same characteristics) between each of the states and an arbitrarily chosen base state. In some degree these differentials reflect cost of living differences, but whether or not they represent differences in real wages, the impact of the minimum wage, itself nominal, depends on its relation to the nominal wage level. We excluded states with less than 10 observations in the sample, leaving 35 states in the MID and in the NLS regressions.

We ran both the semilog and arithmetical wage functions. The former produce percent wage differentials among states, and the latter yield dollar differentials. The two sets of estimates rank identically. We 
Table I

List of Regression Variables

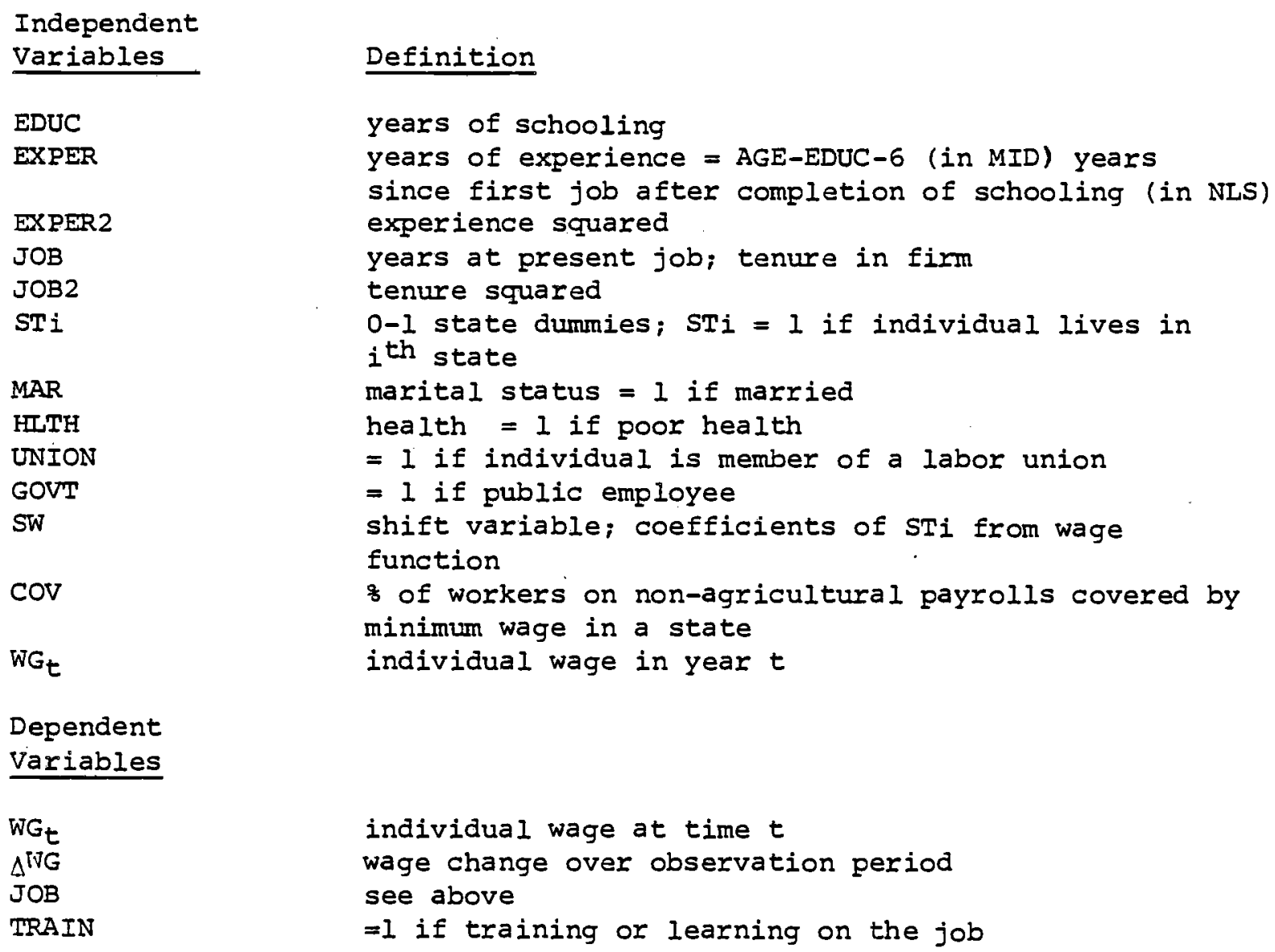

Note: The set of independent variables is the same in all regressions, except that (a) the wage function contains state dummies, but not SW and COV, (b) the wage growth equation has a lagged wage on the right, and (c) the job tenure equation omits job tenure on the right. 
used both sets in the subsequent analyses as alternatives and noticed no clear differences in results. The semilog wage functions showed a somewhat higher $R^{2}$ and a larger contribution of state dummies to $R^{2}$. To save space our Tables show only the partial effects of the combined minimum wage variable: the coverage ratio (cov) divided by the index of the standardized state wage $(I+s w)$. Separate effects of (sw) and of (cov) are shown in the appendix.

Aside from the coefficients on the state dummies, the estimated parameters of the wage functions are similar to those found in many previous studies and are not of primary interest in the present one. The major purpose of the wage regressions here is to estimate the interstate wage differentials. Incidentally, the inclusion of state dummies has little effect on the estimated parameters of the other variables, and it raises the multiple $\mathrm{R}^{2}$ about $25 \%$ (from .34 to .42 ) in the semilog function. Not surprisingly, personal and job characteristics account for most of the "explained" differences in observed (unstandardized) wages among states.

\section{(2). Wage Growth}

The pace at which workers accumulate skills in their work careers is an important factor in producing the upward slope of the typical wage profile. We argue that the rate of skill acquisition, hence wage growth, will be impeded by the level and coverage of minimum wages. Of course, individual skill and wage growth are affected by a number of other factors, such as growth of the economy, the business cycle, level of education and experience, migration and job changes, changes in health and family status, 
and so on. We eliminate the economy-wide factors by studying wage changes of different persons over the same calendar time interval. And we standardize for the other factors, listed in Table 1.

Since the return on investment in human capital is measured in dollars (not in percentages), we used dollar wages to measure absolute growth rather than logarithms to measure percent growth. ${ }^{15}$ Indeed, if the volume of training (measured in dollars) were unaffected after an increase of the minimum wage, with a higher base wage, percentage growth would be diminished. Hence dollar growth provides a more convincing test than percent growth. 16

We analyzed differences in wage growth across individuals in two alternative sets of regressions. For the findings shown in Table 2 (upper panel) we used wages in 1975 as the dependent variable and wages in 1973 as one of the independent variables. Hence, wage growth is shown by differences in 1975 wages, given the wage in 1973. We also ran alternative regressions where our dependent variable is the actual change in wages between 1973 and 1975. The results were quite similar, insofar as our research questions and findings are concerned.

Our hypothesis is that lesser wage growth should be observed in states where standardized wages are lower or the coverage larger. 17

15 The slope of semilog wage functions reflects the ratio of investment (in job training or learning) to earning capacity. Return on the volume of investment is obtained in the arithmetical function, hence the dollar volume of job training is reflected in the slope (growth) of the dollar wage function (cf. Mincer, 1974).

16 We replicated our wage growth regressions in $\log$ form and found the same qualitative results as in our Table 2. Hashimoto (1979) uses percent growth as a test in his empirical model and observes qualitatively similar results.

17Although the correlation is weak, coverage is actually larger in higher wage states. 
The regression estimates in Table 2 indicate the net effects of the minimum wage variable ${ }^{18}$ on wage growth of men with the same education, experience, job tenure, marital status, health status, and union membership.

In the upper panel, which refers to 1973-75 wage growth in the MID, the effects of minimum wages are negative and significant as predicted.

The two lower panels of Table 2 show results of wage growth regressions based on NLS data. These are samples of young men, non-students who were at most 25 years old in 1967. We observe their wage growth in 1967-69 and again in 1969-71. The sample of black youth is large enough in NLS for separate regression analyses. We ran regressions of wages in 1969 and 1971 on the various deteminants as of 1967 and 1969 respectively, including the lagged wage, and the minimum wage variables.

Minimum wage effects are negative and significant for whites in both time periods. They are negative and mainly not significant for blacks. A possible reason for lesser significance of black coefficients is that the components of the minimum wage variable, state wage differentials (sw) and coverage (Cov) could not be estimated separately for blacks.

We would expect the minimum wage to have a stronger impact in lower wage groups within the states. We ran our regressions on progressively smaller subgroups of people with at most high school education (HS) and with less than high school (<HS). Although the samples became smaller, and may therefore lose on statistical significance, we find that the coefficients increase in size, the lower the level of education in the MID panel. The pattern is less clear in NLS.

18 The complete equations are available on request in an appendix. 
Table 2

Effects on Wage Growth

(1). MID Panel, 1973-1975

$\begin{array}{lcrr} & \text { E } & \underline{F} & \underline{\mathrm{n}} \\ \text { All } & -1.547 & 8.50 & 1352 \\ \text { SHS } & -1.936 & 11.77 & 814 \\ \text { <HS } & -2.456 & 8.45 & 318 \\ \text { LHS } & -.819 & .60 & 538\end{array}$

(2). NLS Panel

\section{Whites}

\begin{tabular}{rccc}
$1967-69$ & l & $\underline{F}$ & $\underline{\text { n }}$ \\
AII & -.577 & 3.45 & 802 \\
SHS & -.561 & 2.80 & 637 \\
<HS & -.612 & 1.70 & 275 \\
>HS & -.684 & 0.75 & 165 \\
$1969-71$ & & & \\
\hline AII & & & \\
SHS & -2.21 & 17.5 & 990 \\
<HS & -1.44 & 6.56 & 729 \\
>HS & -2.58 & 9.84 & 267 \\
& -4.60 & 13.35 & 261
\end{tabular}

\section{Blacks}

$\underline{1967-69}$

a $\underline{\mathbf{n}}$

$\begin{array}{cccc}\text { All } & -.410 & .882 & 288 \\ \varsigma_{\text {HS }}^{\text {HS }} & -.647 & 1.97 & 269 \\ <^{H S} & -.423 & .490 & 175\end{array}$

$\underline{1969-71}$

$\begin{array}{llll}\text { All } & -.456 & .489 & 357 \\ S_{\text {HS }} & -.282 & .205 & 332 \\ <\text { HS } & -.899 & 1.50 & 201\end{array}$

$\beta=$ regression coefficients of the minimum wage variable $\left(\frac{\mathrm{Cov}}{I+\mathrm{Sw}}\right)$
$\mathrm{F}=\mathrm{t}^{2}$
$\mathrm{n}=$ number of observations 
As an additional check we singled out the highest education group (13+) in the MID and in the white NLS sample. This group is least likely to be affected by minimum wages in any state. We find that wage growth is not affected by minimum wages in this group in the $1973-75$ period in MID or in the 1967-69 phase among NLS whites. The exception is a reduction in wage growth in the 1969-71 period in NLS.

\section{(3). Job Tenure}

Although on-the-job acquisition of transferable skills has no obvious implications for job turnover, elements of fim specificity in training are likely to strengthen the degree of firm attachment. To the extent that firm specific training is reduced by minimum wages, turnover should increase and job tenure decrease. This implication about minimum wage effects is weaker than the wage growth hypothesis because most acquired skills are largely transferable.

In MID data, which are not restricted to the very young, we find that the length of job tenure is indeed shorter when state wages are lower and coverage larger (Table 3). However, the effect of minimum wage variables on job mobility of white young men in NLS (Table $3 B$ ) is to lengthen job tenure. For NLS blacks minimum wages also appear to reduce tenure, though the coefficients only border on significance.

The difference between NLS and MID in the time periods may represent a distinction between shorter (NLS) and longer-run (MID) effects of the major 1967 changes in minimum wage legislation. In the short run wages 
Table 3

\section{Effects on Job Tenure}

(1). MID Panel, 1973-1975

E $\underline{\underline{n}}$

$\begin{array}{lllr}\text { All } & -4.478 & 8.36 & 1538 \\ \text { SHS } & -5.325 & 5.94 & 913 \\ \text { <HS } & -4.218 & 1.20 & 344 \\ \text { >HS } & -2.899 & 2.00 & 625\end{array}$

(2). NLS Panel

Whites

$1967-69$

AlI

$s^{\text {HS }}$

晶

$\rightarrow \mathrm{HS}$

1969-71
1.94

1.76

2.10

2.10

\section{Blacks}

$1967-69$

All

$3^{\text {HS }}$

$<$ HS

1969-71

All
HSS s

$-1.61$

$-1.35$

$-1.52$

$-1.85$

$-2.14$

$-3.32$
E

2.01

.08

.96

2.45

1.48

.73

2.86

1019

749

265

270

831

650

275

181

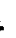


rise but the nature of the job does not change. In that period minimum wages increase layoffs and reduce quits in the covered sector. Twothirds of the separations of young NLS whites are quits, but only half of black separations are quits. Consequently, minimum wages may reduce turnover of young whites, but not of young blacks. In the longer-run, the reduction of training produces an increase in turnover, as in the MID data. The patterns by education are not clear, which leaves the turnover hypothesis uncertain pending further evidence.

\section{(4). Reported Job Training}

Our final test is perhaps the most direct, although the reported data may be a bit more subjective. In the MID we examine answers to a question first posed in 1976: "Do you feel you are learning things on your job that could lead to a better job or to a promotion?" We used a dummy dependent variable with value $I$ if the answer was affirmative and 0 if negative. Prior to 1976 a narrower question was asked only of those with education not exceeding high school. The question was whether during the past year they received any kind of training other than schooling. We ran the 1975 answer as a dumny. The 1976 answers were regressed on the 1975 levels and the 1975 on the 1973 levels of independent variables. The results are shown in Table 4 .

The coeficients of the minimum wage variable are negative, as expected, and increase in size and significance as we move to the lower education groups in the MID panel. 


\section{Table 4}

\section{Effects on Job Training}

(1). MID Panel, 1973-1975

\begin{tabular}{|c|c|c|c|}
\hline & 2 & $\underline{F}$ & $\underline{\mathrm{n}}$ \\
\hline All & -.125 & 1.37 & 1454 \\
\hline$\left\{\leq^{H S}\right.$ & -.220 & 2.34 & 853 \\
\hline$<$ HS & -.391 & 2.81 & 310 \\
\hline$>$ HS & +.014 & .01 & 601 \\
\hline 175 HS & -.443 & 10.23 & 1011 \\
\hline
\end{tabular}

(2). NLS Panel

Whites

$1967-69$

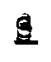

F

$\underline{\mathrm{n}}$

$\begin{aligned} & \text { AII } \\ & \leq \text { HS } \\ &<\text { HS } \\ &>\text { HS }\end{aligned}$

$-.128$

$(2.25)$

(2.60)

$(.408)$

1089

$-.140$

$-.058$

$(.009)$

$+.026$

1969-71

All
3 HS
$<$ HS
$>$ HS
$-.180$

$-.196$

$-.245$

$-.128$

Blacks

$1967-69$

All

$\leq$ HS

$<$ HS

$\underline{1969-71}$
量

$-.148$

$-.139$

.011
(2.75)

$(2.68)$

$(2.60)$

(.270)
1183

882

319

301

AII
$\leq$ HS
$<H S$

.064
-.0114
.011

(.857)

488

$(4.20)$

448

$(.000)$

270

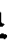


In the NLS sample of young men, we coded answers of those who received training on the current job. The concept of training is narrower than in MID, as it appears to refer to formal rather than all training. The minimum wage reduces training in both racial groups and time periods. The coefficients are significant in most cases. No effects are observed in the more educated (13+ years) subsample in MID and in NLS.

The NLS data contain some information on job training off the firm, excluding school. We might expect the minimum wage to encourage such training as an alternative to in-firm training, though not to (publicly subsidized) schooling. In regressions not shown here, the coefficients were generally not statistically significant, but most of the signs were in the predicted direction, that is positive.

On the whole, the findings in the NLS regressions tend to be favorable to our hypothesis, although they are not as strong as the findings in MID.

\section{(5). Conclusions}

The hypothesis that minimum wages tend to discourage on the job training is largely supported by our empirical analysis. Direct effects on job training and the corollary effects on wage growth as estimated (in Tables 4 and 2 , respectively) are consistently negative and stronger at lower education levels. Indeed, apart from a single exception, no effects are observable among the higher wage group whose education exceeds high school. 
The effects on job turnover are: a decrease in turnover among young NLS whites, but an increase among young NLS blacks and MID whites. Whether these apparently conflicting findings on turnover reflect a distinction between short and long run adjustments in jobs is a question that requires further testing. 


\section{References}

R. G. Ehrenberg and A. Marcus, "Minimum Wage Legislation and the Educational Decisions of Youth," forthcoming in Research in Labor Economics, August 1979.

M. Feldstein, "Lowering the Permanent Rate of Unemployment," Joint Economic Committee of Congress, September 1973.

R. Freeman and J. L. Medoff, "The Youth Labor Market Problem in the U.S.," paper prepared for NBER Conference, May 1979.

M. Hashimoto, "Minimum Wage and Earnings Growth of Young Males," Econometric Society Meeting, December 1979.

J. P. Mattila, "Youth Labor Markets, Enrollments, and Minimum Wages," IRRA Proceddings, August 1978.

- "The Impact of Minimum Wages on School Enrollment and Labor Force Status of Youths," Report to DOL, June 1979.

J. Mincer, "Unemployment Effects on Minimum Wages," NBER Working Paper No. 357, Part II, August 1976.

J. Mincer and B. Jovanovic, "Labor Mobility and Wages," NBER Working Paper No. 357 , June 1979.

J. W. Mixon, Jr., "The Minimum Wage and Voluntary Labor Mobility," Industrial and Labor Relations Review, October 1978.

S. Rosen, "Learning by Experience in the Labor Market," Journal of Human Resources, Summer 1972.

R. Swidinsky, "Minimum Wages and Teenage Unemployment in Canada," CIRRI Meeting, London, May 1978.

U.S. Department of Labor Wage and Hour Division, Minimum Wages and Maximum Hours Standards under FLSA, Washington, 1970.

M. Wachter and S. Kim, "Time Series Changes in Youth Joblessness," NBER Working Paper No. 384, August 1979.

F. Welch, "Minimum Wage Legislation in the U.S.," Economic Inquiry, September 1974.

W. Wessels, "The Effects of Minimum Wages on Firm Expenditures," Mimeo, North Carolina State University, 1979.

E. G. West and M. McKee, "The Economics of Minimum Wages with Special Reference to Canada; A Review," Carleton University, February 1979. 


\section{Appendix Tables}

Separate Effects of State Wage Differentials (Sw) and of Coverage (Cov)

\section{Table 2a}

A. Wage Growth 1973-1975 (White Men in MID)

\begin{tabular}{|c|c|c|c|c|c|c|c|c|c|}
\hline & & Iagc & Wage & & & Cha & Wage & & \\
\hline & & W & & & & & & & $\mathrm{n}$ \\
\hline & $\mathrm{b}$ & $F$ & $\mathrm{~b}$ & $\bar{F}$ & $\vec{b}$ & $F$ & $\mathrm{~b}$ & $F$ & \\
\hline 11 & 1.36 & 10.0 & -.48 & .23 & .94 & 5.1 & -.52 & .26 & 1352 \\
\hline HS & 1.75 & 14.4 & -.69 & .40 & 1.48 & 11.1 & -.70 & .41 & 814 \\
\hline$<\mathrm{HS}$ & 2.33 & 11.0 & -.61 & .13 & 1.77 & 6.9 & -.61 & .13 & 318 \\
\hline
\end{tabular}

B. Wage Growth 1967-1969, and 1969-1971 (Young Men in NLS)

(Lagged Wage Specification)

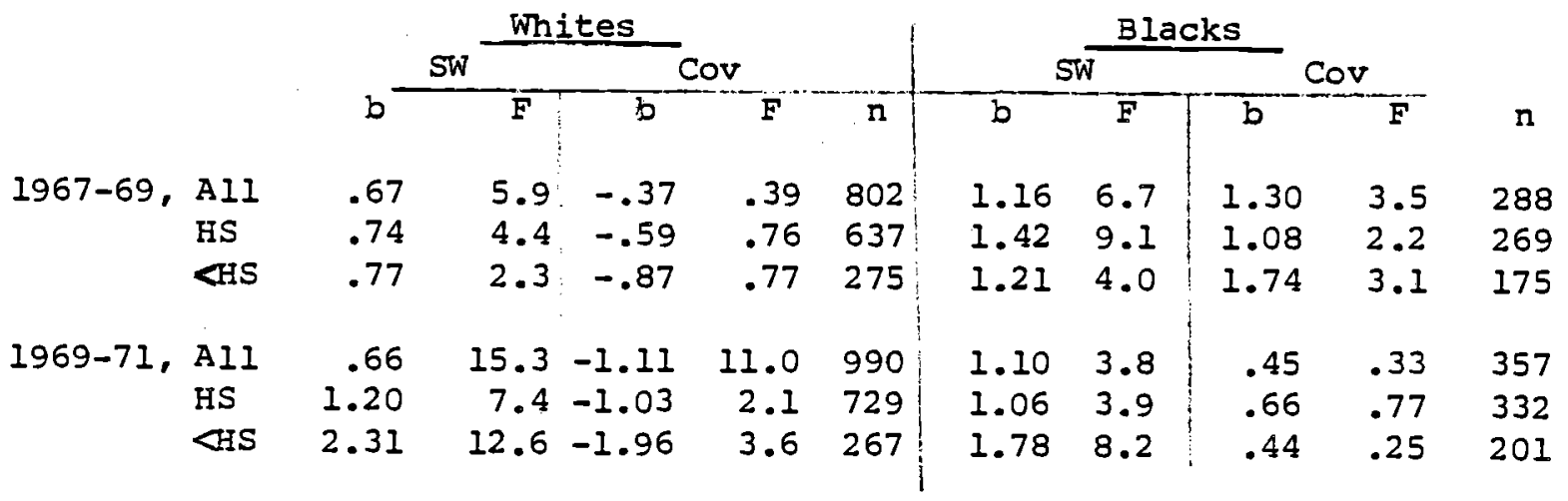




\section{Table $3 a$}

\section{Length of Job Tenure}

A. MID, 1975

\begin{tabular}{|c|c|c|c|c|c|}
\hline & \multicolumn{2}{|c|}{ SW } & \multicolumn{2}{|c|}{ Cov } & \multirow[b]{2}{*}{$\mathrm{n}$} \\
\hline & $b$ & $F$ & $b$ & $F$ & \\
\hline$A \overline{11,1975}$ & 3.30 & 7.1 & -8.12 & 7.2 & 1538 \\
\hline HS & 4.05 & 5.3 & -9.86 & 5.2 & 913 \\
\hline$<\mathrm{HS}$ & 2.66 & .70 & -14.67 & 3.4 & 344 \\
\hline
\end{tabular}

B. NLS

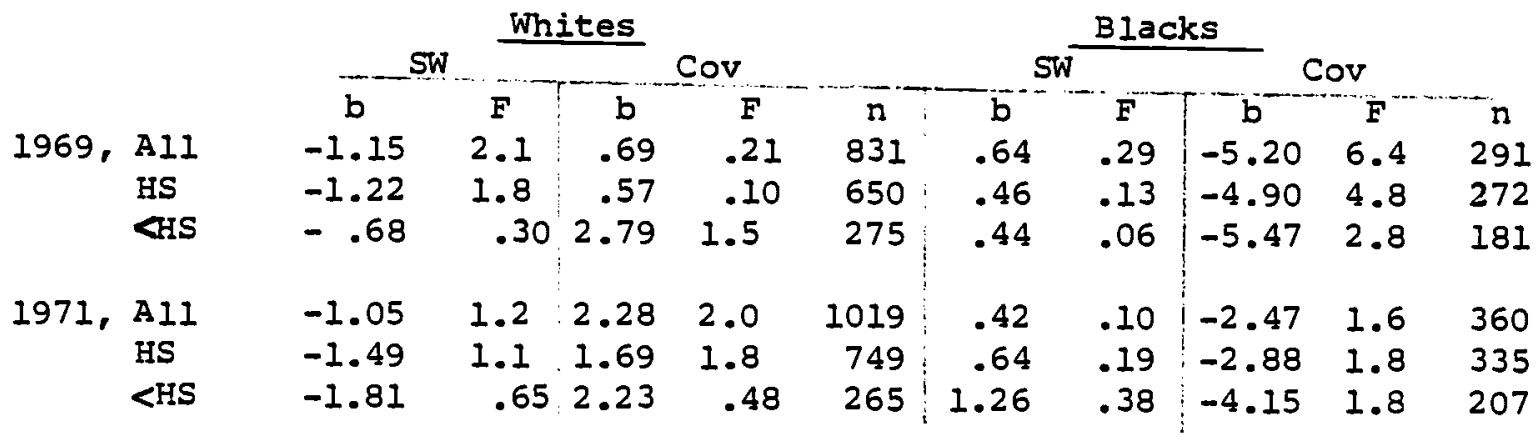




\section{Table $4 a$}

In Firm Training On Current Job

A. MID 1976, 1975

\begin{tabular}{lccccc} 
& \multicolumn{2}{c}{ SW } & \multicolumn{3}{c}{ Cov } \\
1976 , Al1 & b & F & b & F & n \\
HS & .08 & .95 & -.40 & 3.8 & 1454 \\
<HS & .12 & 1.1 & -.69 & 5.3 & 853 \\
& .30 & 2.5 & -.50 & 1.1 & 310 \\
1975 , HS & .40 & 13.3 & -.05 & .13 & 1011
\end{tabular}

B. NLS, 1969 and 1971

\begin{tabular}{|c|c|c|c|c|c|c|c|c|c|c|}
\hline & \multicolumn{4}{|c|}{ Whites } & \multicolumn{4}{|c|}{ Blacks } & \multirow{2}{*}{\multicolumn{2}{|c|}{ Cov }} \\
\hline & \multicolumn{2}{|c|}{ SW } & \multicolumn{2}{|c|}{ Cov } & \multicolumn{4}{|c|}{$s \bar{w}$} & & \\
\hline & $b$ & $F$ & $\mathrm{~b}$ & $F$ & $\mathrm{n}$ & $\mathrm{b}$ & $F$ & $\mathrm{~b}$ & $F$ & $n$ \\
\hline 969 , Al1 & .15 & 2.7 & -.06 & .14 & 1089 & .17 & 5.2 & -.088 & .54 & 431 \\
\hline HS & .18 & 3.8 & -.06 & .12 & 861 & .16 & 4.9 & -.09 & .64 & 408 \\
\hline$<\mathrm{HS}$ & .07 & .45 & -.16 & .68 & 371 & .03 & .25 & .10 & 1.56 & 268 \\
\hline 71, A11 & .16 & 3.3 & -.06 & .23 & 1183 & .04 & 0.51 & -.07 & .64 & 488 \\
\hline HS & .19 & 4.2 & -.12 & .007 & 882 & .07 & 2.1 &.- .14 & 4.4 & 448 \\
\hline$<H S$ & .21 & 3.3 & -.20 & 1.00 & 319 & -.00 & .00 & -.01 & .02 & 270 \\
\hline
\end{tabular}

